\title{
President's New Year greeting
}

\author{
Majda M. Thurnher ${ }^{1}$
}

Published online: 29 December 2015

(C) Springer-Verlag Berlin Heidelberg 2015

Dear Friends,

Dear Colleagues,

2015 is coming to a successful close....

In just a few years the ESNR has grown tenfold. Now, we are much better prepared to adapt to socio-economic changes and professional challenges in the future with agility.

The guiding principles of the ESNR are education, curriculum, certification, and cooperation. ESNR focuses on education as we all ardently believe in fully integrating and embedding teaching activities into everything our society does. Ultimately, our goal is to do much more than train well-educated, clinical neuroradiologists; we need and will train outstanding practitioners who can serve our patients' best interests.

Our courses welcome all radiologists: those who need to acquire basic knowledge, those who are in training to become 'true' neuroradiologists, and those whose ambition it is to advance in certain subfields of neuroradiology. We can all be proud of the Pierre Lasjaunias Course in neuroradiology. It is clearly a success story!

We have witnessed a steady increase in the numbers of participants, which reached 300 . At every one of our courses and meetings, we can celebrate a common achievement in increasing the number of non-European participants. In a few short years, the ESNR has truly become an international society.

Majda M. Thurnher

majda.thurnher@meduniwien.ac.at

1 Department of Radiology, Medical University of Vienna, Waehringer Guertel 18-20, 1090 Vienna, Austria

We have reached a new milestone: our European Board of Neuroradiology was founded. The Board is responsible for all examinations, certifications, and diplomas in Neuroradiology in Europe. The standards protect our discipline from those who may acquire a smattering of knowledge, yet do not have profound expertise and experience. The European Board of Neuroradiology has a vital mission: to establish the European Diploma in Neuroradiology as an internationally recognized certificate of neuroradiological excellence.

The ESNR will continue to increase cooperation with other scientific societies, both within and beyond Europe. Our firmly established collaboration with the American Society of Neuroradiology, the American Society of Spine Radiology, and the American Society for Pediatric Neuroradiology have clearly shown that we can learn from each other, and have much to gain from developing joint projects.

Our Society is inclusive and will keep encouraging all those who want to join our welcoming family. We will continue to be progressive and will seek to drive innovation to advance neuroradiology in the future. We will continue to support young colleagues who want to become neuroradiologists.

We have overcome challenges in the past and will together master new ones. Let us not forget that ESNR defends the best interests of neuroradiologists. This is necessary now because we confront a worrisome trend. Other disciplines are appropriating certain aspects of our discipline. These aspects cannot be separated from the whole without the loss of knowledge, expertise, and quality in diagnosis and care. Quality medical care depends upon the full contribution of our discipline. We 
must close our ranks to prevent outsourcing and to sustain this discipline. Our field has been and will remain at the very cutting edge of what is exciting in medicine today.

We are now more than 3000 professionals pursuing a single goal: to ensure the very best neuroradiological practice. I am confident we will succeed in our mission. Thank you for your trust as we are aware of this great responsibility
I wish you all Happy Holidays and a successful 2016.

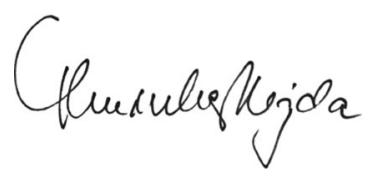

Majda M. Thurnher

President, ESNR 